\title{
Potentially inappropriate prescribing in institutionalised older patients in Spain: the STOPP-START criteria compared with the Beers criteria
}

Amalia UBEDA, M. Luisa FERRÁNDIZ, Nuria MAICAS, Cristina GOMEZ, Montserrat BONET, Jose E. PERIS. Received (first version): 4-Jul-2011

Accepted: 11-Apr-2012

\begin{abstract}
${ }^{*}$
Objective: The aims of this study were to identify potentially inappropriate prescribing using the Beers and STOPP criteria. The START criteria were applied to detect prescription omission in the geriatric population. We compared the utility of these criteria in institutionalised older people. Methods: Descriptive study reviewing the medication and clinical records of 81 residents (aged 65 years and more) by pharmacists in a nursing home in the Lleida region (Spain). Results: The mean patients' age was $84(S D=8)$ years, with an average of 5 drugs per resident (total prescriptions: 416 medicines). The Beers criteria identified potentially inappropriate medication use in $25 \%$ of patients and $48 \%$ of patients used at least 1 inappropriate medication according to STOPP criteria. The most frequent potentially inappropriate medications for both criteria were long-acting benzodiazepines and NSAIDs. START detected 58 potential prescribing omissions in $44 \%$ of patients. Calcium-vitamin D supplementation in osteoporosis was the most frequent rule (15\%), but omissions corresponding to the cardiovascular system implied $23 \%$ of patients.

Conclusion: The STOPP-START criteria reveal that potentially inappropriate prescribing (PIP) is a highly prevalent problem among Spanish nursing home residents, and a statistically significant positive correlation was found between the number of medicines prescribed and the number of PIP detected in this study. The STOPP criteria detect a larger number of $\mathrm{PI}$ medications in this geriatric population than the Beers criteria. The prescribing omissions detected by the START criteria are relevant and require intervention. Pharmacists' review of medications may help identify potentially
\end{abstract}

\footnotetext{
Amalia UBEDA. PhD. Department of Pharmacology. Faculty of Pharmacy, University of Valencia (Spain). M. Luisa FERRÁNDIZ. PhD. Department of Pharmacology. Faculty of Pharmacy, University of Valencia (Spain).

Nuria MAICAS. PhD. Department of Pharmacology. Faculty of Pharmacy, University of Valencia (Spain). Cristina GOMEZ. Community Pharmacy. Seu d'Urgell, Lleida (Spain).

Montserrat BONET. General Practitioner. Seu d'Urgell, Lleida (Spain).

Jose E. PERIS. PhD. Department of Pharmacy and

Pharmaceutical Technology, Division of Biopharmaceutics and Pharmacokinetics. Faculty of Pharmacy, University of Valencia (Spain).
}

inappropriate prescribing and, through an interdisciplinary approach, working with physicians may improve prescribing practices among geriatric residents of nursing homes

Keywords: Inappropriate Prescribing. Aged. Nursing Homes. Spain.

\section{PRESCRIPCIÓN POTENCIALMENTE INAPROPIADA EN ANCIANOS INSTITUCIONALIZADOS EN ESPAÑA: LOS CRITERIOS STOPP-START COMPARADOS CON LOS CRITERIOS DE BEERS}

\section{RESUMEN}

Objetivo: Este estudio está orientado a identificar la prescripción potencialmente inapropiada usando los criterios de Beers y STOPP. Las omisiones de prescripciones se detectan en esta población geriátrica aplicando los criterios START. Se compara la utilidad de estos criterios en ancianos institucionalizados.

Métodos: Estudio descriptivo de revisión de la medicación y las historias clínicas por farmacéuticos, de 81 pacientes (con 65 o más años) ingresados en una residencia en la provincia de Lleida (España).

Resultados: La media de edad de los pacientes fue de 84 años $(\mathrm{DE}=8)$, con cinco medicamentos de promedio de tratamiento por residente (prescripciones totales: 416 medicamentos). Los criterios de Beers detectaron el uso de medicación potencialmente inapropiada en el $25 \%$ de los pacientes. Los criterios STOPP identificaron una posible medicación inapropiada en el $48 \%$ de los pacientes. La mayor frecuencia de uso de medicamentos potencialmente inapropiados para ambos criterios correspondió a las benzodiacepinas de larga duración y los AINE. Los criterios START detectaron 58 prescripciones potencialmente omitidas en el $44 \%$ de los pacientes. Entre ellas, la ausencia de suplementos de Calcio-vitamina D en osteoporosis fue la regla más frecuentemente implicada ( $15 \%$ de los pacientes); sin embargo, las omisiones relacionadas con el sistema cardiovascular asociadas a elevado riesgo cardiovascular son las que implicaron hasta un $23 \%$ de pacientes.

Conclusión: La aplicación de los criterios STOPPSTART ha detectado una elevada proporción de prescripciones potencialmente inapropiadas en 
pacientes ancianos en una residencia sanitaria en España, con una significativa correlación positiva entre el número de medicamentos prescritos al paciente y el número de prescripciones potencialmente inapropiadas. Los criterios STOPP identificaron más medicación potencialmente inapropiada que los criterios de Beers. Las omisiones detectadas por los criterios START son relevantes y requiere una intervención. La revisión de la medicación por un farmacéutico puede ayudar a identificar potenciales prescripciones

inapropiadas y, con un abordaje interdisciplinario, en colaboración con los médicos se podría mejorar la prescripción en pacientes ancianos de residencias geriátricas.

Palabras clave: Prescripción Inadecuada. Anciano. Residencias de ancianos. España.

\section{INTRODUCTION}

In developed countries, the demographic trend moves towards a society with populations with increasing percentages of citizens aged 65 years and more. ${ }^{1}$ In Spain, the geriatric population represents $17 \%$ of the total population. ${ }^{2}$ Consequently, there is a heavy health burden as this population corresponds to more than $70 \%$ of the total prescription costs in the Spanish National Health System in $2008 .^{3}$ In Europe, the amount of healthcare resources used by the older citizens is more than double that consumed by the general population. $^{4}$

Chronic diseases and multiple medical conditions predominate in older citizens; consequently, there is a high prevalence of polypharmacy, defined as the use of multiple medications which has been associated with negative health outcomes. ${ }^{5}$ Pharmacokinetics and pharmacodynamics changes in older people are of much relevance in dose regimes. Lack of awareness of these changes can contribute to inappropriate medicines use, which can cause adverse drug effects. Besides, some of these reactions may be confused with progression of the given pathology or with some typical agerelated syndromes. ${ }^{1}$

A potentially inappropriate medication (PIM) is assumed when the risk of adverse effects outweighs the expected clinical benefit, especially when a safer or more effective alternative therapy is available for the same condition. PIMs use is a major problem among older people, and may contribute to increased risk of adverse drug effects and to developing drug-drug and drug-disease interactions. $^{6,7}$

Appropriate prescribing can be assessed by explicit indicators developed by consensus approaches. The most commonly used explicit criteria to review drug treatments and to identify PIMs are the Beers criteria. This tool includes a list of inappropriate drugs that should be avoided in older patients because of toxicity relating to the agent, toofrequent doses or too-large accumulative daily doses (independent of diagnosis), plus a list of criteria considering diagnoses with possible drugdisease interactions. ${ }^{8}$ Although the Beers criteria have been applied widely in many studies to define potentially inappropriate medications use in older people, several studies considered that these criteria present a number of serious flaws (e.g., many proscribed drugs are not used in European formularies, inclusion of some drugs is subject to controversy, and the criteria do not contemplate problems involving under-used beneficial medicines) and are of doubtful relevance to routine geriatric pharmacotherapy, especially in European countries. ${ }^{7,9}$ For these reasons, the new PIP criteria have been devised and validated (STOPP: Screening Tool of Older Persons' Prescriptions; and START: Screening Tool to Alert to Right Treatment) to detect potential errors in prescribing and the omission of well-indicated medication in the geriatric population. ${ }^{10}$ Recently, these criteria have been adopted by the European Union Geriatric Medicine Society, and have been translated into several European languages. ${ }^{11,12}$

Older residents in nursing homes are often frail, with progressive degenerative health problems and frequent polypharmacy. Their dependency and frequent cognitive impairment undermine their capacity to report adverse drug events. A recent study indicated that living in an institutional setting was associated with an increased risk of PIPs in older citizens with mental co-morbidities admitted to hospitals. ${ }^{13}$ This highlights the need for regular reviews and adjustments of the treatments taken by this geriatric population. By means of a pharmaceutical care service, pharmacists can help detect potential medication problems and improve medication selection appropriateness in older people. $6,14,15$

The aims of this study were to identify firstly PIMs using the Beers and the STOPP criteria and secondly errors of omission using the START criteria in nursing home residents; to compare the utility of these screening tools in measuring PIP in institutionalised older people; to determine the relationship between the number of prescribed drugs and PIPs; and to highlight those drugs that frequently contribute to most PIPs in Spanish nursing home residents.

\section{METHODS}

A cross-sectional restrospective 6-month study was performed in 2008 with patients aged 65 years and above, who were residents of a nursing home in the Lleida region (Spain). For each resident, medical and prescriptions records were reviewed, and patients were included if they had regular systemic medication prescriptions (including inhaled route medicines) and completed clinical diagnosis records; thus, 81 patients ( $98 \%$ of all the residents) were selected during the study period.

A search of PIPs in residents' medical charts was done by a pharmacist applying both the Beers and the STOPP-START criteria. The pharmacist was not directly involved in these patients' medical care. 
PIPs were identified using the Beers criteria (2003) (independently of diagnoses and considering diagnoses or clinical conditions) and the STOPPSTART criteria. The STOPP section includes 65 indicators considered to be PIMs, while the START section has 22 indicators of potentially prescribing omissions in older people. Patients' diagnoses were obtained from medical charts (and were also verified with prescribed medication and analytical values). A minimum 6 month periodical assessment of each patient's clinical conditions was done by the physician. Some residents were assessed with a higher frequency (e.g., measurements of $\mathrm{HbA} 1 \mathrm{C}$ and/or fasting glucose levels in diabetics patients were assessed weekly or biweekly depending on diabetes type and insulinotherapy).

Flunitrazepam was also considered a PIM because it is a Benzodiazepine marketed in Spain with similar pharmacological properties to other longacting benzodiazepines, although it was not explicit on the Beers list.

Age, gender, functional status (the Barthel index ${ }^{16}$ ), mental status (MMSE adapted by Lobo ${ }^{17}$ ) and number of chronically prescribed medications, were also recorded. The study protocol was approved by both the responsible clinician and the residence's administration in charge. Informed consents were not required from participants due to their deidentification and lack of direct involvement.

A descriptive analysis of the results for each criterion was done by measuring not only the number of the subjects with PIPs as identified by each tool, but also the number of inappropriateness criteria identified in each patient. To determine statistical correlations between the number of medicines prescribed, age, gender, mental status, Barthel Index and the PIPs, bivariate correlations for nonparametric data were calculated (Spearman's $\rho$ correlation coefficient). The Wilcoxon signed rank test for nonparametric data was used to compare the PIPs using the Beers criteria and STOPP. The Pearson's chi-square test was used to compare the occurrence of PIPs between males and females, and Barthel index and MMSE. In all statistical tests, a probability value of $<0.05$ was considered significant.

\section{RESULTS}

Table 1 summarises the characteristics of the 81 patients prescribed at least one regular systemically acting medicine in the nursing home. The mean age of the participating residents was $84(\mathrm{SD}=8)$ years, $63 \%$ were female and the majority $(70 \%)$ of patients were 80 years of age, or more. The mean number of medicines prescribed per residents was 5.1 $(S D=2.6)$, with a total number of 416 medicines prescribed. Polypharmacy (that is, at least 5 chronic prescriptions per patient) was detected in $54 \%$ of participants. Most residents displayed a low degree of dependence (Barthel Index $\geq 60$ ), but $48 \%$ presented severe cognitive impairment (MMSE score $\leq 24$ ).

After applying all the inappropriateness criteria, 50\% of patients used at least one PIM to be avoided ( 41

\begin{tabular}{|c|c|}
\hline Age, mean (SD) & $84(8)$ \\
\hline Range & $65-98$ years \\
\hline Gender & $\begin{array}{c}63 \% \text { female } \\
(51 / 81)\end{array}$ \\
\hline Number of medication prescribed & 416 \\
\hline Prescription medication per resident (SD) & $5.1(2.6)$ \\
\hline Range & $1-11$ \\
\hline \multicolumn{2}{|l|}{ Barthel index } \\
\hline Mean (SD) & $\begin{array}{c}57(35) \\
\text { Range 0- } \\
100\end{array}$ \\
\hline $\begin{array}{r}\geq 60 \text { (independence or minor dependence } \\
\text { in ADL) }\end{array}$ & $65 \%$ \\
\hline 40-55 (moderate limitation) & $15 \%$ \\
\hline$\leq 35$ (disability or severe limitation in $\mathrm{ADL}$ ) & $20 \%$ \\
\hline \multicolumn{2}{|l|}{ Mini-Mental Status Examination } \\
\hline Mean (SD) & $\begin{array}{c}21(12) \\
\text { Range } 0-35\end{array}$ \\
\hline$\geq 30$ & $30 \%$ \\
\hline 25-29 (minor cognitive impairment) & $22 \%$ \\
\hline$\leq 24$ (severe cognitive impairment) & $48 \%$ \\
\hline ADL: activities daily & \\
\hline
\end{tabular}

patients) with a prevalence of $23 \%$ of inappropriate prescriptions. Table 2 summarises the PIM distribution per patient. The STOPP criteria detected a larger number of patients with any PIM $(48 \%)$ than the Beers criteria $(25 \%)$. The STOPP criteria also detected a larger number of patients with two or more PIMs than Beers. Thus, a total of $62 \%$ of the patients had any PIP according to the STOPP-START criteria, while $64 \%$ of the patients had any PIP when considering all three criteria.

According to Beers, independently of diagnosis, the most frequently inappropriate drugs use was: longacting benzodiazepines ( 7 patients). When considering a diagnosis in a person with gastric or duodenal ulcers, use of conventional NSAIDs was the most widely prescribed contraindicated drug (4 patients). Overall, the Beers criteria identified 13 PIMs (independently of diagnosis) in $15 \%$ of patients. Furthermore, and in relation to disease, the Beers criteria identified 17 PIMs in $19 \%$ of patients (Table 3 ). A statistically significant positive correlation was found between the number of medicines prescribed and the number of PIMs detected using the Beers criteria $\left(r_{s}=0.383\right.$, $\mathrm{P}<0.001)$. The number of PIMs identified was significantly lower using Beers $(7 \%$ of total prescriptions in $25 \%$ patients) than STOPP $(16 \%$ of total prescriptions in $48 \%$ of patients) (Wilcoxon signed-ranks test $Z=-3.775, P<0.001)$, despite both containing a similar number of rules.

The number of PIMs identified by STOPP was 66 in $48 \%$ of patients. Of the 65 criteria, only 16 identified a PIM. The highest prevalence (22) was related to the central nervous system (15 relating to

Table 2. Number of patients identified with a potential inappropriate medicine (PIMs) according to the Beers and STOPP criteria and a potential prescribing omission (PPOs) by the START criteria in 81 patients.

\begin{tabular}{|c|c|c|c|}
\hline Num. patients & Beers & STOPP & START \\
\hline One inappropriate & 11 & 22 & 22 \\
\hline Two & 8 & 11 & 8 \\
\hline Three & 1 & 4 & 4 \\
\hline 4 or more & -- & 2 & 2 \\
\hline $\begin{array}{c}\text { Patients with any } \\
\text { PIM-PPO (\%) }\end{array}$ & $20(25 \%)$ & $39(48 \%)$ & $36(44 \%)$ \\
\hline
\end{tabular}




\begin{tabular}{|c|c|c|}
\hline BEERS CRITERIA & : Independent of diagnosis & \\
\hline Amiodarone & & 1 \\
\hline $\begin{array}{l}\text { Long-acting benzodiazepine } \\
\text { - Diazepam } \\
\text { - Chlorazepate } \\
\text { - Flunitrazepam }\end{array}$ & & $\begin{array}{l}2 \\
4 \\
1\end{array}$ \\
\hline $\begin{array}{l}\text { Long-term long half-life NSA } \\
\text { - Indomethacin } \\
\text { - Ketorolac }\end{array}$ & IDs & $\begin{array}{l}1 \\
1\end{array}$ \\
\hline Antidepressant & & \\
\hline - Fluoxetine (daily) & & 2 \\
\hline Cerebral Vasodilators & & \\
\hline - Dihydroergocristine - Pira $^{\text {b }}$ & cetam & 1 \\
\hline & TOTAL & 13 \\
\hline BEERS CRITERI & A: Considering diagnosis & \\
\hline Diagnosis & DRUG & \\
\hline Gastric or duodenal ulcers & $\begin{array}{l}\text { NSAIDs and aspirin (>325 } \\
\mathrm{mg})\end{array}$ & 4 \\
\hline Bladder outflow obstruction & Antidepressant (fluoxetine) & 1 \\
\hline Stress incontinence & Long-acting benzodiazepines & 3 \\
\hline Parkinson disease & Conventional antipsychotics & 1 \\
\hline Depression & $\begin{array}{l}\text { Long-term benzodiazepine } \\
\text { use }\end{array}$ & 1 \\
\hline Syncope or falls & $\begin{array}{l}\text { Short-to intermediate acting } \\
\text { benzodiazepine }\end{array}$ & 3 \\
\hline COPD & $\begin{array}{l}\text { Long-acting benzodiazepines } \\
\text { (chlorazepate) }\end{array}$ & 1 \\
\hline Constipation & Calcium channel blockers & 3 \\
\hline & TOTAL & 17 \\
\hline $\begin{array}{l}\text { 'Long-acting benzodiazepin } \\
\text { 'Beers criteria indicated "ers } \\
\text { NSAIDs: nonsteroidal anti-ir } \\
\text { COPD: Chronic obstructive } \\
\text { Patients' diagnoses were } \\
\text { (included analytical values a } \\
\text { Tendency to falls was assig } \\
\text { in the last year. }\end{array}$ & $\begin{array}{l}\text { not included in the Beers list. } \\
\text { ot mesyloids" } \\
\text { flammatory drugs. } \\
\text { pulmonary disease. } \\
\text { recorded from medical cha } \\
\text { nd prescribed pharmacotherapie } \\
\text { eed if patients had at least two fal }\end{array}$ & \\
\hline
\end{tabular}

neuroleptics), followed by drugs for the cardiovascular system (18) (Table 4). PIMs of NSAIDs accounted for 13 cases, but they corresponded to seven patients: six with hypertension and one with heart failure. NSAIDs also contributed to two cases of duplicate drug class prescriptions. The Beers criteria considered that NSAIDs were to be avoided with gastric or duodenal ulcers (four patients). In contrast, STOPP did not apply this criterion (E1) for the concurrent use of proton pump inhibitors (PPI), following clinical guideline recommendations, thus allowing treatment to proceed in these four patients. This approach is more flexible than that of the Beers criteria. Besides, STOPP details particular instances where prescription of NSAIDs is potentially inappropriate; e.g., heart failure, hypertension, prolonged treatment for osteoarthritis, gout or chronic renal failure. A statistically significant positive correlation was found between the number of medicines prescribed and the number of PIM calculated using STOPP $\left(r_{s}=0.296, P<0.01\right)$. Besides, a significant positive correlation was found between age and the number of PIM calculated using STOPP $\left(r_{s}=0.256\right.$, $P<0.05)$ but was not significant using the Beers criteria. A higher number of PIMs detected by the STOPP criteria was presented in females than in males $\left(r_{s}=0.230, P<0.05\right)$. In fact, the occurrence of PIMs in females $(54.9 \%)$ was more frequent than in males $(36.7 \%)$, although the difference was not statistically significant (Pearson's chi-square test).

A statistically significant negative correlation was found between the Barthel Index and the cognitive impairment (MMSE) scores, and the number of PIM when the STOPP criteria were applied $\left(r_{s}=-0.330\right.$, $P<0.01, r_{s}=-0.097, P<0.05$, respectively). In fact, for those patients without cognitive impairment, the occurrence of PIMs using the STOPP criteria (27\%) was less frequent than in patients with moderate or severe cognitive impairment $(50 \%$ and $55 \%$, respectively). However, the correlation was not statistically significant (Pearson's chi-square test).

The START criteria identified a total of 58 omissions of potentially needed drugs in $44 \%$ of patients. The most frequent was lack of calcium and vitamin $D$ supplementation in osteoporosis (15\%; 12 patients) (Table 5). The cardiovascular system accounted for several problems: statins therapy was omitted in $17 \%$ of patients from both the cardiovascular and endocrine perspectives. Among those residents with high risk cardiovascular conditions, $12 \%$ did not receive prophylactic treatment with anticoagulants, aspirin or antiplatelet therapy (10 omissions). Overall, the number of potential prescribing omissions corresponding to the cardiovascular system, plus major cardiovascular risk factors (statins and antiplatelet therapy), involved $23 \%$ of the patients. Of the 22 START criteria, only 13 identified all the potential omissions. A statistically significant positive correlation was found between the number of medicines prescribed and the number of potential omissions ( $r s=0.300, P<0.01$ ). However, the relationships between age or gender or the Barthel Index or the cognitive impairment score (MMSE) and the number of potential omissions were not significant.

The START criteria were formulated to be used in tandem with STOPP to provide a more complete assessment of PIPs. ${ }^{10}$ We detected a possible incongruence between two STOPP-START items. When applying the STOPP criteria, we detected three diabetic patients with a PIM in relation to rule A13 (Aspirin use with no history of coronary, cerebral or peripheral vascular symptoms). However, if the physician decided to suppress aspirin prescription according to this PIM rule, when applying the START criteria, we could consider that aspirin had been omitted for these patients in accordance with rule F3 (antiplatelet therapy in diabetes with co-existing major cardiovascular risk factors). For this reason, these three diabetic patients were not considered to receive a PIM according to STOPP rule A13.

\section{DISCUSSION}

Inappropriate prescribing is a frequent, serious global health problem in older citizens. This study indicates that the PIM rate among Spanish nursing home residents is high; i.e., $48 \%$ with the STOPP criteria, and $25 \%$ with the Beers criteria. The prevalence of PIM among nursing home patients, using the Beers criteria, range from $28 \%$ to $37 \%$ in European studies $^{18-20}$ and are even higher in US 


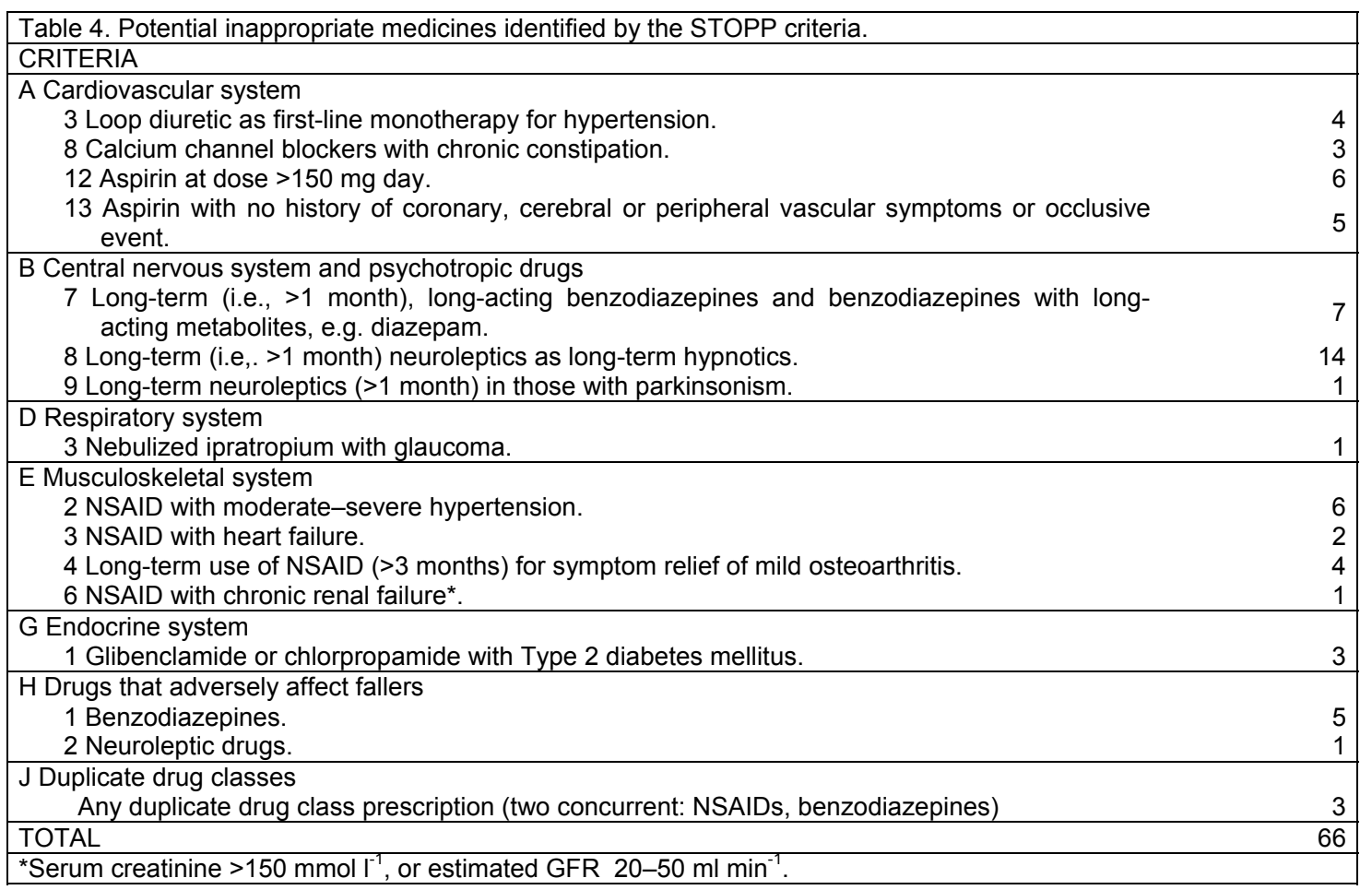

studies $^{21,22}$, showing differences in drug availability and prescribing practices. Spanish data identify a PIM prevalence that ranges from $20 \%$ to $35 \%$ patients among nursing home residents when applying the Beers criteria ${ }^{23,24}$, and from a $50 \%$ to $65 \%$ of the patients with at least one of the STOPP criteria $^{23,25}$ or even higher rates when the study included additional criteria (low-utility drugs). ${ }^{26}$ Our study obtained a PIM prevalence of $25 \%$ patients with the Beers criteria, although several drugs in the list are not available in Spain, or are rarely prescribed nowadays. The PIM prevalence identified by Beers was similar to the range referred to in other European studies using the Beers criteria. $^{18-20}$ However, comparisons are not easy because different set of criteria are applied and given the various study settings.

Both the STOPP and the Beers criteria contain a similar number of PIM rules. Nevertheless only 11 patients were simultaneously detected by both criteria. The overlap was related to rules about benzodiazepines, neuroleptics, NSAIDs and calcium channel blockers. Beers also detected more patients with PIMs relating to the use of NSAIDs than STOPP because Beers did not consider the concurrent use of PPI (omeprazol), which is a serious shortcoming in this Beers rule.

The PIMs obtained with the STOPP criteria included $48 \%$ of our patients, with a lower prevalence that ranges from $50 \%$ to $65 \%$ patients found in Spanish institutional settings. ${ }^{23,25}$ The STOPP criteria proved more sensitive for the detection of PIMs than Beers, and STOPP also detected more adverse drugs events causing hospitalisation than Beers. ${ }^{6,27}$ This suggests that the STOPP criteria may be a more relevant inappropriateness detection tool than the Beers criteria as many avoidance drugs are no longer available in Spain, and some other criteria showed discrepancies with more recent guidelines (i.e., NSAIDs prescription associated with a PPI, as indicated previously).

Almost $60 \%$ of the PIMs detected by STOPP involve benzodiazepines, neuroleptics and NSAIDs. Chronic use of benzodiazepines has been described in more than $30 \%$ of Spanish elderly women $^{28}$, and long-acting benzodiazepines are prescribed more than short-acting benzodiazepines among Spanish retired people. ${ }^{29}$ Long-acting benzodiazepines have been frequently highlighted as inappropriate, particularly concerning the risk of falls and fractures and their contribution to mental deterioration. ${ }^{30,31}$ Thus, they represent a significant preventable risk for older people's health. The prevalence of using inadequate psychotropic drugs in the Spanish institutionalised population was $12.5 \%$, with diazepam as one of the most often prescribed drugs. ${ }^{32}$ Benzodiazepines use in older people was also one of the most common potential problems identified in many studies. . $^{25,33,34}$ Psychotropic medication is extensively used in Australian nursing homes for indications other than schizophrenia. ${ }^{35}$ Long-acting benzodiazepines, and the simultaneous administration of two psychotropic drugs from the same therapeutic class, were frequently involved in patients with adverse drug reactions admitted to a geriatric hospital. ${ }^{36}$

The STOPP criteria were significantly associated with avoidable adverse drug events that caused or contributed to patients' hospitalization. ${ }^{27}$ This finding has significant implications for hospital geriatric practice. In nursing homes, some authors have found a correlation between inappropriate medication use (the Beers criteria) and occurrence of an adverse health outcome. ${ }^{21}$

By applying the STOPP criteria in our study, three cases of item $J$ (any duplicated drug class prescriptions due to a concurrent use of 2 NSAIDs and 2 benzodiazepines) were detected. This 
Table 5. Potential prescribing omissions identified by the START criteria

CRITERIA

A Cardiovascular system

1 y 2 Warfarin (Acenocumarol) or Aspirin in the presence of chronic atrial fibrillation (AF).

5 Statin therapy with a documented history of coronary, cerebral or peripheral vascular disease,

where the patient's functional status remains independent for activities of daily living and life expectancy is $>5$ years.

6 Angiotensin converting enzyme (ACE) inhibitor with chronic heart failure.

B Respiratory system

1 Regular inhaled beta 2 agonist or anticholinergic agent for mild to moderate asthma or chronic obstructive pulmonary disease (COPD).

C Central nervous system

1 L-DOPA in idiopathic Parkinson's disease with definite functional impairment and resultant disability

2 Antidepressant drug in the presence of moderate-severe depressive symptoms lasting at least 3 months.

D Gastrointestinal system

1 Proton pump inhibitor with severe gastro-oesophageal acid reflux disease

2 Fibre supplement for chronic, symptomatic diverticular disease with constipation.

E Musculoskeletal system

3 Calcium and Vitamin D supplement in patients with known osteoporosis.

F Endocrine system

1 Metformin with Type 2 diabetes (in the absence of renal impairment ${ }^{\star}$ ).

3 Antiplatelet therapy in diabetes mellitus with co-existing major cardiovascular risk factors

(hypertension, hypercholesterolaemia, smoking history).

4 Statin therapy in diabetes mellitus if co-existing major cardiovascular risk factors present.

TOTAL Potential prescribing omissions

*Serum creatinine $>150 \mathrm{mmol}$ l-1, or estimated GFR 20-50 ml min-1.

unnecessary drug duplication is one of the problems frequently detected in primary care patients with polypharmacy, together with incorrect dose and therapy duration. ${ }^{37}$ Potentially inappropriate medication use was associated in our study with the use of multiple medications. Polypharmacy was one of the factors relating to potentially inappropriate medications in a multicenter European study with older patients receiving home care ${ }^{30}$ and in another Irish primary care study.

The START criteria detected clinical situations of potentially inappropriate omissions. The present study found omissions in $44 \%$ of patients. Very few studies have applied these criteria in nursing homes, although two recent Spanish studies detected prevalences of $30 \%$ and $46 \%$ in this setting. ${ }^{23,25}$ The majority of these omissions involved calcium and vitamin D supplements in osteoporosis, plus statins and low-dose aspirin, similar to other underutilization studies. ${ }^{23,25,39,40}$ A deficient ingestion of calcium and vitamin $D$ in osteoporosis has been highlighted in antiresorptive therapy. As regards cardiovascular omissions, doubts about the efficacy of statins in very elderly patients can be a reason for the non-prescription of these drugs. ${ }^{41}$ However, low-dose aspirin in secondary prevention morbidity and mortality has evidenced benefits. ${ }^{42}$ Several studies have reported a link between an underuse of cardiovascular medicines and adverse health outcomes. ${ }^{43,44}$

The STOPP criteria were formulated to be used in tandem with START to provide a more complete assessment of PIMs and prescribing omissions. ${ }^{10}$ We detected a possible incongruence between two STOPP-START items related to aspirin use (as an antiplatelet agent). In a diabetic patient, a STOPP rule for avoidance of aspirin use (A13) must not overlap the necessity of this medication according to the START rule (F3) of antiplatelet therapy for diabetes with major cardiovascular risk factors, as indicated in the Results section.
In this study, we found a positive relationship between the number of medicines and occurrence of potential omissions. Similar underprescribing correlating to polypharmacy was indicated in a geriatric ward study based on drug therapy omission according to clinical practice guidelines, which showed a higher frequency of underprescribing in drugs advised to prevent cardiovascular diseases. This may mean that polypharmacy can dissuade prescribers from adding more medicines. In contrast, an Irish primary care study based on the START criteria did not find this relationship. Our study did not show a statistically correlation between potential omission and mental status, age or gender.

The present study is not without some methodological limitations. A small sample size and the specific setting with a unique physician limit the results from being generalised. The population was cared for by a non-geriatrician practitioner and comprised patients who are representative of nursing homes (advanced old age, predominance of women and polypharmacy (54\% taking at least 5 medicines), and many residents had mental health deterioration with similar characteristics to residents in other nursing home-based studies. ${ }^{25,46}$ Only pharmacists were involved in the review of prescriptions, lack of complete patient clinical data may limit the full application of tools and can overestimate or underestimate PIPs. This study highlights the possible problems in nursing home patients including a frequently understated aspect of prescribing omission. It ought to be remembered that PIPs detected by explicit criteria cannot be considered a real problem until a clinician judges that individual patient's adequacy in his/her exact situation.

Different approaches to improve prescribing among older patients have been undertaken in several settings. Some studies have shown that the positive contribution of pharmacists can help enhance 
medication management in polypharmacy and older patients, and can improve patient outcomes. ${ }^{7,15,47}$ Recently, Gallagher and co-workers have shown significant improvements in prescribing appropriateness by applying the STOPP/START criteria as an intervention process in hospitalized older patients. ${ }^{48}$ Sotoca et al. similarly applied the STOPP/START criteria in nursing home residents, reported PIPs to the responsible physician and obtained a modification of medical prescriptions in $53 \%$ of the patients. ${ }^{25}$ The practical application of the STOPPISTART criteria in community pharmacy has not yet been established. These tools may apply to medication reviews when dispensing drugs following pharmaceutical care services with a view to identifying situations which entail alerting nursing home physicians. Nonetheless, lack of complete patient clinical data may limit these criteria from being fully applied in community pharmacy. Besides, criteria could be adapted to primary care computer prescribing systems and be updated in line with new therapeutic evidence. We believe that items have to be also adapted and revalidated for contextual differences among countries. In any case, the systematic application of those explicit criteria will never substitute clinical assessments and clinicians' judgements. With these tools, however, pharmacists can alert physicians to consider whether medication is a possible cause of adverse health outcomes in older people.

\section{CONCLUSIONS}

The application of the STOPP-START criteria showed that PIP is a highly prevalent problem in nursing home residents. The STOPP criteria detect a larger number of patients with PIMs than the Beers criteria in this geriatric population. START also detected many patients who did not receive adequate drug treatments for their diseases. Pharmacists can assist in a comprehensive appraisal of older patients' medications using the STOPP-START criteria, which would benefit patients through elimination of potentially inappropriate medication and identification of potential medication omissions to optimize patient care.

\section{CONFLICT OF INTEREST}

None.

\section{References}

1. Stegemann S, Ecker F, Maio M, Kraahs P, Wohlfart R, Breitkreutz J, Zimmer A, Bar-Shalom D, Hettrich P, Broegmann B. Geriatric drug therapy: Neglecting the inevitable majority. Ageing Res Rev. 2010;9:(4)384-398.

2. Instituto Nacional de Estadística. Avance padrón municipal 2011. Available at: http://www.ine.es/prensa/np648.pdf (Accessed 20 April 2011).

3. Consejo General de Colegios Oficiales de Farmacéuticos. Estadísticas Sanitarias 2008 España. pag 34. Available at: http://www.portalfarma.com/pfarma/taxonomia/general/ gp000016.nsf/voDocumentos/120C1F228EDEF914C125764E00352390/\$File/estadisticas_sanitarias.pdf (Accessed 20 April 2011).

4. O'Neill C, Hughes CM, Jamison J, Schweizer A. Cost of pharmacological care of the elderly: Implications for healthcare resources. Drugs Aging. 2003;20(4):253-261.

5. Hajjar ER, Cafiero AC, Hanlon JT. Polypharmacy in elderly patients. Am J Geriatr Pharmacother. 2007;5(4):345-351.

6. Gallagher P, O'Mahony D. STOPP (screening tool of older persons' potentially inappropriate prescriptions): Application to acutely ill elderly patients and comparison with Beers' criteria. Age Ageing. 2008;37(6):673-679.

7. Spinewine A, Schmader KE, Barber N, Hughes C, Lapane KL, Swine C, Hanlon JT. Appropriate prescribing in elderly people: How well can it be measured and optimised? Lancet. 2007;370(9582):173-184.

8. Fick DM, Cooper JW, Wade WE, Waller JL, Maclean JR, Beers MH. Updating the Beers criteria for potentially inappropriate medication use in older adults: Results of a US consensus. Arch Intern Med. 2003;163(22):2716-2724.

9. O'Mahony D, Gallagher P, Ryan C, Byrne S, Hamilton H, Barry P, O'Connor M, Kennedy J. STOPP \& START criteria: A new approach to detecting potentially inappropriate prescribing in old age. Eur Geriatr Med 2010;1(1):45-51.

10. Gallagher P, Ryan C, Byrne S, Kennedy J, O'Mahony D. STOPP (screening tool of older person's prescriptions) and START (screening tool to alert doctors to right treatment). Consensus validation. Int J Clin Pharmacol Ther. 2008;46(2):72-83.

11. Delgado Silveira E, Muñoz García M, Montero Errasquin B, Sánchez Castellano C, Gallagher PF, Cruz-Jentoft AJ. Prescripción inapropiada de medicamentos en los pacientes mayores: Los criterios STOPP/START. Rev Esp Geriatr Gerontol. 2009;44(5):273-279.

12. Lang PO, Hasso Y, Belmin J, Payot I, Baeyens JP, Vogt-Ferrier N, Gallagher P, O'Mahony D, Michel JP. STOPPSTART: Adaptation of a French language screening tool for detecting inappropriate prescriptions in older people. Can J Public Health. 2009;100(6):426-431.

13. Lang PO, Hasso Y, Drame M, Vogt-Ferrier N, Prudent M, Gold G, Pierre Michel J. Potentially inappropriate prescribing including under-use amongst older patients with cognitive or psychiatric co-morbidities. Age Ageing. 2010;39(3):373381.

14. Spinewine A, Swine C, Dhillon S, Lambert P, Nachega JB, Wilmotte L, Tulkens PM. Effect of a collaborative approach on the quality of prescribing for geriatric inpatients: A randomized, controlled trial. J Am Geriatr Soc. 2007;55(5):658665.

15. Loganathan M, Singh S, Franklin BD, Bottle A, Majeed A. Interventions to optimise prescribing in care homes: Systematic review. Age Ageing. 2011;40(2):150-162. 
Ubeda A, Ferrándiz ML, Maicas N, Gomez C, Bonet M, Peris JE. Potentially inappropriate prescribing in institutionalised older patients in Spain: the STOPP-START criteria compared with the Beers criteria. Pharmacy Practice (Internet) 2012 Apr-Jun;10(2):83-91

16. Cabanero-Martinez MJ, Cabrero-Garcia J, Richart-Martinez M, Munoz-Mendoza CL. The spanish versions of the Barthel index $(\mathrm{BI})$ and the Katz index $(\mathrm{KI})$ of activities of daily living (ADL): A structured review. Arch Gerontol Geriatr. 2009;49(1):e77-e84.

17. Lobo A, Saz P, Marcos G, Dia JL, de la Camara C, Ventura T, Morales Asin F, Fernando Pascual L, Montanes JA, Aznar S. Revalidation and standardization of the cognition mini-exam (first Spanish version of the Mini-Mental Status Examination) in the general geriatric population. Med Clin (Barc). 1999;112(20):767-774.

18. Hosia-Randell HM, Muurinen SM, Pitkala $\mathrm{KH}$. Exposure to potentially inappropriate drugs and drug-drug interactions in elderly nursing home residents in Helsinki, Finland: A cross-sectional study. Drugs Aging. 2008;25(8):683-692.

19. Ruggiero C, Lattanzio F, Dell'Aquila G, Gasperini B, Cherubini A. Inappropriate drug prescriptions among older nursing home residents: The Italian perspective. Drugs Aging. 2009;26(Suppl 1):15-30.

20. Byrne S, Ryan C, O'Mahony D, Weedle P, Kennedy J, Ahern E. Inappropriate prescribing in the elderly: a review of primary care and nursing home prescriptions. Int J Pharm Pract. 2008;16(Suppl 1): A36-A37.

21. Perri $M 3^{\text {rd }}$, Menon AM, Deshpande AD, Shinde SB, Jiang R, Cooper JW, Cook CL, Griffin SC, Lorys RA. Adverse outcomes associated with inappropriate drug use in nursing homes. Ann Pharmacother. 2005;39(3):405-411

22. Liu GG, Christensen DB. The continuing challenge of inappropriate prescribing in the elderly: An update of the evidence. J Am Pharm Assoc. 2002;42(6):847-857.

23. Conejos Miquel MD, Sanchez Cuervo M, Delgado Silveira E, Sevilla Machuca I, Gonzalez-Blazquez S, Montero Errasquin B, Cruz-Jentoft AJ. Potentially inappropriate drug prescription in older subjects across health care settings. Eur Geriatr Med. 2010;1(1):9-14.

24. Fidalgo García ML, Molina García T, Millán Pacheco F, Orozco Díaz P, Benavente Moreda I, Casado López M, López Bilbao C. Prescripción farmacéutica en residencias de ancianos. Comparación con ancianos ambulatorios. Medifam. 2001;11(2):55-70

25. Sotoca JM, Anglada H, Molas G, Fontanals S, Rovira M, Sebastian L. Aplicación de los nuevos criterios de prescripción inadecuada STOPP-START a pacientes geriátricos institucionalizados. Farm Aten Primaria. 2011;9(1):2-7.

26. Gongora L, Puche E, Garcia J, Luna JD. Inappropriate prescriptions in elderly residents of nursing homes. Rev Esp Geriatr Gerontol. 2004;39(1):19-24.

27. Hamilton H, Gallagher P, Ryan C, Byrne S, O'Mahony D. Potentially inappropriate medications defined by STOPP criteria and the risk of adverse drug events in older hospitalized patients. Arch Intern Med. 2011;171(11):1013-1019.

28. Bejarano Romero F, Pinol Moreso JL, Mora Gilabert N, Claver Luque P, Brull Lopez N, Basora Gallisa J. Increased benzodiazepine use in elderly women attending urban primary health care centers. Aten Primaria. 2008;40(12):617-621.

29. Barbera T, Avellana JA, Moreno Royo L. Are benzodiazepines correctly used in the elderly? Rev Clin Esp. 2007;207(3):138-140.

30. Wang PS, Bohn RL, Glynn RJ, Mogun H, Avorn J. Hazardous benzodiazepine regimens in the elderly: Effects of halflife, dosage, and duration on risk of hip fracture. Am J Psychiatry. 2001;158(6):892-898.

31. Tinetti ME. Clinical practice. preventing falls in elderly persons. N Engl J Med. 2003;348(1):42-49.

32. Sicras-Mainar A, Pelaez-de-Lono J, Castella-Rosales A, Rodriguez-Darriba M. Consumption of inappropriate psychotropic drugs in residential homes for the elderly: Comparative study between 2001 and 2006 . Farm Hosp. 2008;32(2):96-101.

33. Ryan C, O'Mahony D, Kennedy J, Weedle P, Byrne S. Potentially inappropriate prescribing in an Irish elderly population in primary care. Br J Clin Pharmacol. 2009;68(6):936-947.

34. Pattanaworasate W, Emmerton L, Pulver L, Winckel K. Comparison of prescribing criteria in hospitalised Australian elderly. Pharm Pract (Internet). 2010;8(2):132-138.

35. Snowdon J, Day S, Baker W. Current use of psychotropic medication in nursing homes. Int Psychogeriatr. 2006;18(2):241-250.

36. Laroche ML, Charmes JP, Nouaille Y, Picard N, Merle L. Is inappropriate medication use a major cause of adverse drug reactions in the elderly? Br J Clin Pharmacol. 2007;63(2):177-186.

37. Chang LF, Lutfiyya MN, El-Khabiry E. Results of chart reviews conducted to evaluate primary care patients seen by second and third year family medicine residents for potential adverse polypharmacy. Pharm Pract (Internet). 2007;5(2):85-88

38. Fialova D, Topinkova E, Gambassi G, Finne-Soveri H, Jonsson PV, Carpenter I, Schroll M, Onder G, Sorbye LW, Wagner C, Reissigova J, Bernabei R, AdHOC Project Research Group. Potentially inappropriate medication use among elderly home care patients in Europe. JAMA. 2005;293(11):1348-1358.

39. Kamel HK. Underutilization of calcium and vitamin D supplements in an academic long-term care facility. J Am Med Dir Assoc . 2004;5(2):98-100

40. Barry PJ, Gallagher P, Ryan C, O'Mahony D. START (screening tool to alert doctors to the right treatment)--an evidence-based screening tool to detect prescribing omissions in elderly patients. Age Ageing. 2007;36(6):632-638.

41. Kvan E, Pettersen KI, Landmark K, Reikvam A, INPHARM study investigators. Treatment with statins after acute myocardial infarction in patients $>$ or $=80$ years: Underuse despite general acceptance of drug therapy for secondary prevention. Pharmacoepidemiol Drug Saf. 2006;15(4):261-267.

42. Spinler SA. Safety and tolerability of antiplatelet therapies for the secondary prevention of atherothrombotic disease. Pharmacotherapy. 2009;29(7):812-821.

43. Masoudi FA, Rathore SS, Wang Y, Havranek EP, Curtis JP, Foody JM, Krumholz HM. National patterns of use and effectiveness of angiotensin-converting enzyme inhibitors in older patients with heart failure and left ventricular systolic dysfunction. Circulation. 2004;110(6):724-731.

44. Soumerai SB, McLaughlin TJ, Spiegelman D, Hertzmark E, Thibault G, Goldman L. Adverse outcomes of underuse of beta-blockers in elderly survivors of acute myocardial infarction. JAMA. 1997;277(2):115-121. 
Ubeda A, Ferrándiz ML, Maicas N, Gomez C, Bonet M, Peris JE. Potentially inappropriate prescribing in institutionalised older patients in Spain: the STOPP-START criteria compared with the Beers criteria. Pharmacy Practice (Internet) 2012 Apr-Jun;10(2):83-91.

45. Kuijpers MA, van Marum RJ, Egberts AC, Jansen PA, OLDY (OLd people Drugs \& dYsregulations) Study Group. Relationship between polypharmacy and underprescribing. Br J Clin Pharmacol. 2008;65(1):130-133.

46. Martin-Baranera M, Sanchez Ferrin P, Armario P, Geriatric HTA Study Group. Prevalence of hypertension in elderly long-term care residents in Spain. the geriatric HTA study. Med Clin (Barc). 2006;127(18):681-687.

47. Marcum ZA, Handler SM, Wright R, Hanlon JT. Interventions to improve suboptimal prescribing in nursing homes: A narrative review. Am J Geriatr Pharmacother. 2010;8(3):183-200.

48. Gallagher PF, O'Connor MN, O'Mahony D. Prevention of potentially inappropriate prescribing for elderly patients: A randomized controlled trial using STOPP/START criteria. Clin Pharmacol Ther. 2011;89(6):845-854. 